\title{
Synthesis of a Copper 1,3,5-Triamino-2,4,6-Benzenetriol Metal-Organic Framework
}

Yi Jiang, ${ }^{1, \#}$ Inseon Oh, ${ }^{3,}$ \# Se Hun Joo, ${ }^{4, ~}{ }^{\#}$ Yu-Seong Seo, ${ }^{5}$ Sun Hwa Lee, ${ }^{1}$ Won Kyung Seong, ${ }^{1}$ Yu Jin Kim, ${ }^{4}$ Jungseek Hwang,,${ }^{5}$ * Sang Kyu Kwak,,${ }^{4,}$ * Jung-Woo Yoo, ${ }^{3,}$ * and Rodney S. Ruoff ${ }^{1,2,3,4, *}$

${ }^{1}$ Center for Multidimensional Carbon Materials (CMCM), Institute for Basic Science (IBS), Ulsan 44919, Republic of Korea

${ }^{2}$ Department of Chemistry, Ulsan National Institute of Science and Technology (UNIST), Ulsan 44919, Republic of Korea

${ }^{3}$ Department of Materials Science and Engineering, Ulsan National Institute of Science and Technology (UNIST), Ulsan 44919, Republic of Korea

${ }^{4}$ School of Energy and Chemical Engineering, Ulsan National Institute of Science and Technology (UNIST), Ulsan 44919, Republic of Korea

${ }^{5}$ Department of Physics, Sungkyunkwan University, Suwon, Gyeonggi-do 61419, Republic of Korea

\#These authors were equal major contributors.

*Email: correspondence and requests for materials should be addressed to R.S.R. (rsruoff@ibs.re.kr; ruofflab@gmail.com), S.K.K. (skkwak@unist.ac.kr), J.-W.Y. (jwyoo@unist.ac.kr),orJ.H. (jungseek@skku.edu). 


\section{Methods}

FT-IR measurements were made using an Agilent 600 Series FT-IR spectrometer. XPS data were obtained using an ESCALAB 250Xi XPS. Nitrogen sorption analysis was carried out using a surface area and porosity analyzer (Micromeritics ASAP2020); the sample was degassed under vacuum at $100{ }^{\circ} \mathrm{C}$ for $10 \mathrm{~h}$ before any measurement. Powder XRD patterns were collected on a Rigaku SmartLab powder X-ray diffractometer. Elemental analysis was conducted on a Thermo Scientific ${ }^{\mathrm{TM}}$ FLASH 2000 organic elemental analyzer. Electrical properties were measured in a Quantum Design Physical Property Measurements System with the help of an external electrometer (Keithley 2636A and 2182) with high impedance. A pressed $\mathrm{Cu}_{3}(\mathrm{TABTO})_{2}-\mathrm{Ar}$ pellet $(5 \times 8 \mathrm{~mm}$ and $0.15 \mathrm{~mm}$ thick) was prepared and stored in air for electrical measurements. The electrical conductivity of this type of sample was measured in a vacuum to avoid condensation, e.g., of oxygen or moisture or other components of air that could condense on the sample. Four-terminal Ti $(5 \mathrm{~nm}) / \mathrm{Au}$ $(100 \mathrm{~nm})$ contacts with $1 \mathrm{~mm}$ separations were deposited by thermal evaporation. Electrical contacts to the Au pads were made using Ag paste to copper wires. Raman spectroscopy (Wi-Tec micro Raman) was done under $532 \mathrm{~nm}$ laser excitation under ambient conditions. The infrared reflectance measurements were performed using a FT-IR type spectrometer Vertex 80v (Bruker, Germany). SEM was performed with an FEI Verios 460 SEM. TEM was carried out at a Joel JEM-2100F TEM instrument. Synchrotron X-ray diffraction (XRD) measurements were performed at the PLS-II 6D UNIST-PAL beamline of the Pohang Accelerator Laboratory in Pohang, Republic of Korea. The energy of the X-rays was $18.981 \mathrm{keV}$ corresponding to a wavelength of $0.6532 \AA$. A Bruker Dimension Icon AFM instrument was used to measure the thicknesses of the films on $300 \mathrm{~nm} \mathrm{SiO} / \mathrm{Si}$ 
substrates. 1,3,5-Triamino-2,4,6-benzenetriol was synthesized using a previously reported procedure. $^{1}$

\section{Synthesis of $\mathrm{Cu}_{3}(\mathrm{TABTO})_{2}$}

Cu3(TABTO)2-Ar: $\mathrm{Cu}\left(\mathrm{NO}_{3}\right) 2 \cdot 3 \mathrm{H}_{2} \mathrm{O}(112.2 \mathrm{mg}, 0.6 \mathrm{mmol})$ and ethylenediamine $(73 \mu \mathrm{L}$, $1.1 \mathrm{mmol}$ ) were dissolved in $15 \mathrm{~mL}$ degassed $\mathrm{H}_{2} \mathrm{O}$ under Ar. In a separate flask, 1,3,5triamino-2,4,6-benzenetriol (TABTO, $55.8 \mathrm{mg}, 0.2 \mathrm{mmol}$ ) was dissolved in $15 \mathrm{~mL}$ degassed $\mathrm{H}_{2} \mathrm{O}$ and then transferred via cannula to the copper solution under vigorous stirring. The reaction was kept at $80{ }^{\circ} \mathrm{C}$ for 2 days under the Ar. The solid was collected by filtration and washed with THF, water, and methanol. The obtained solid was dried under high vacuum $\left(10^{-3}\right.$ torr $)$ for 8 hours.

Cu3(TABTO)2-Air-1 and 2: $\mathrm{Cu}\left(\mathrm{NO}_{3}\right) 2 \cdot 3 \mathrm{H}_{2} \mathrm{O}(112.2 \mathrm{mg}, 0.6 \mathrm{mmol})$ and ethylenediamine (73 $\mu \mathrm{L}, 1.1 \mathrm{mmol})$ were dissolved in $15 \mathrm{~mL}$ degassed $\mathrm{H}_{2} \mathrm{O}$. In a separate flask, 1,3,5triamino-2,4,6-benzenetriol (TABTO, $55.8 \mathrm{mg}, 0.2 \mathrm{mmol}$ ) was dissolved in $15 \mathrm{~mL}$ degassed $\mathrm{H}_{2} \mathrm{O}$ and then transferred via cannula to the copper solution under vigorous stirring. The reaction was kept at $80{ }^{\circ} \mathrm{C}$ for 2 days in air. The solid was collected by filtration and washed with THF, water, and methanol. The obtained solid was dried under high vacuum $\left(10^{-3}\right.$ torr) for 8 hours. When the reaction was exposed to air without stirring, the sample $\left(\mathrm{Cu}_{3}(\mathrm{TABTO})_{2}\right.$-Air-2) was obtained.

\section{Synthesis of iodine-doped $\mathrm{Cu}_{3}(\mathrm{TABTO})_{2}$-Ar and -Air-1}

An open container $(5.0 \mathrm{~mL})$ containing pristine $\mathrm{Cu}_{3}(\mathrm{TABTO})_{2}$-Air $(100 \mathrm{mg})$ or $\mathrm{Cu}_{3}$ (TABTO) $)_{2}$-Air-1 powder $(100.0 \mathrm{mg}, 0.19 \mathrm{mmol}$ based on a theoretical formula of $\left.\mathrm{Cu}_{3}(\mathrm{TABTO})_{2}\right)$ was placed in a bigger container $(15.0 \mathrm{~mL})$ containing iodine $(2.0 \mathrm{~g}, 7.9$ 
mmol). The bigger container was sealed tightly with a cap and heated at $65^{\circ} \mathrm{C}$ for 8 hours. The as-synthesized iodine-doped $\mathrm{Cu}_{3}(\mathrm{TABTO})_{2}$ powder was washed with separate amounts of $n$-hexane, followed by drying under vacuum $\left(10^{-3}\right.$ Torr $)$ for $8 \mathrm{~h}$, to remove unreacted iodine. 


\section{Elemental analysis}

Table S1. Elemental analysis of $\mathrm{Cu}_{3}(\mathrm{TABTO})_{2}$-Air-1.

\begin{tabular}{|c|c|c|c|}
\hline \multirow[b]{2}{*}{ Sample } & \multicolumn{3}{|c|}{ Calculated } \\
\hline & Element & (wt\%) & Found (wt\%) \\
\hline & $\mathrm{C}$ & 24.06 & 23.79 \\
\hline $\mathrm{Cu}_{3}(\mathrm{TABTO})_{2}$ & $\mathrm{~N}$ & 14.03 & 13.87 \\
\hline$\left[\mathrm{C}_{12} \mathrm{H}_{12} \mathrm{~N}_{6} \mathrm{O}_{6} \mathrm{Cu}_{3} \cdot\left(\mathrm{H}_{2} \mathrm{O}\right)_{4}\right]_{n}$ & $\mathrm{H}$ & 3.37 & 2.58 \\
\hline & $\mathrm{O}$ & 26.71 & 28.31 \\
\hline
\end{tabular}

We note that the value of hydrogen is lower than expected, because most of the amine groups were oxidized to $-\mathrm{C}=\mathrm{NH}$ as we described in the main text. 


\section{XPS spectra of $\mathrm{Cu}_{3}(\mathrm{TABTO})_{2}-\mathrm{Ar}$.}
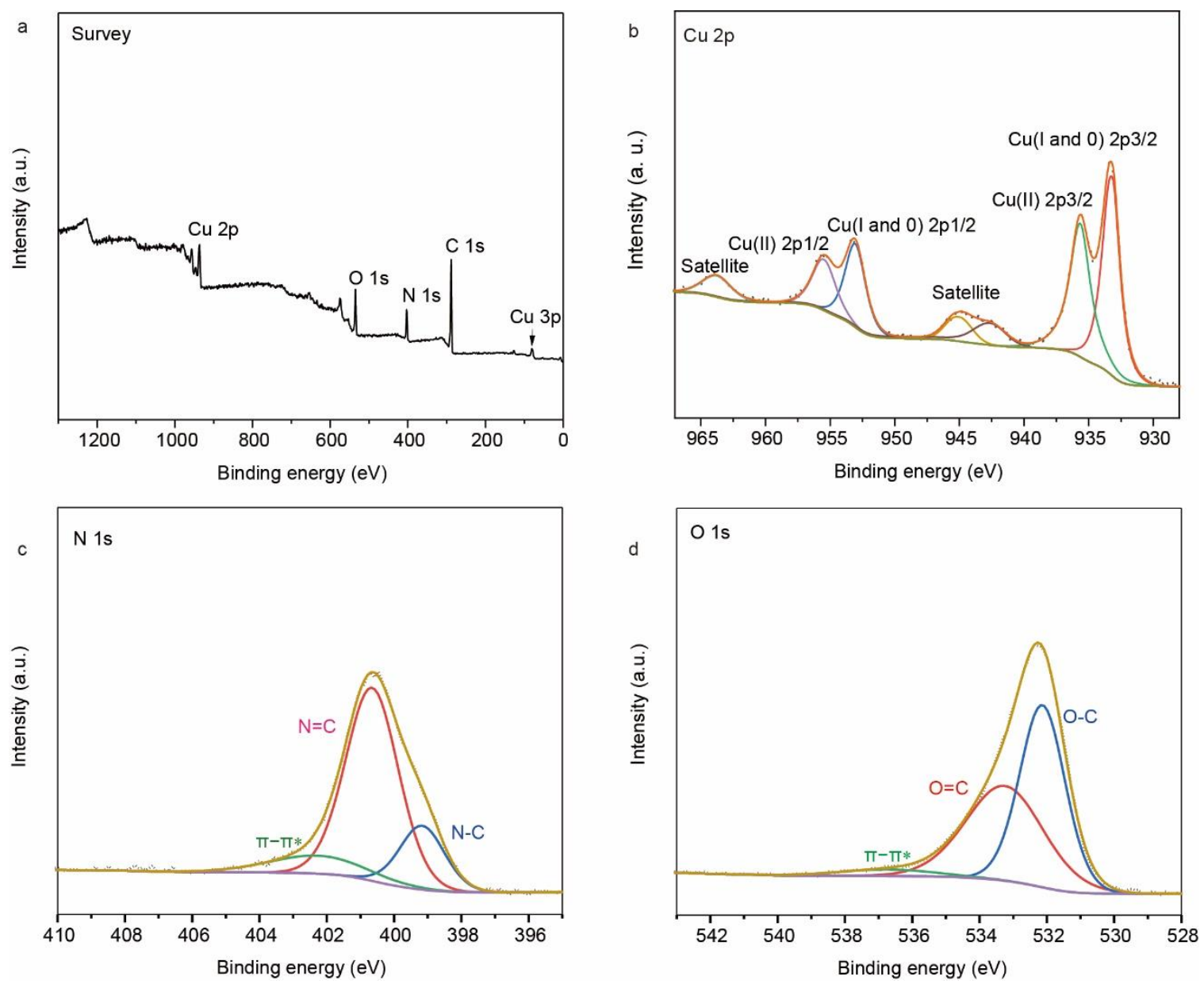

Figure S1. XPS spectra of $\mathrm{Cu}_{3}(\mathrm{TABTO})_{2}-\mathrm{Ar}$. The atom ratio of $\mathrm{Cu}(\mathrm{II})$ and $\mathrm{Cu}(\mathrm{I}$ and 0$)$ is $4 / 5$. 


\section{Density functional theory calculations}

Spin-polarized density functional theory (DFT) calculations were performed using the Vienna $a b$ initio simulation package (VASP). ${ }^{2,3}$ Electronic wave functions were expanded in the plane-wave basis set with a kinetic energy cutoff of $550 \mathrm{eV}$. The electron-ion interaction was described using the projector-augmented-wave (PAW) method. ${ }^{4}$ The generalized gradient approximation with the Perdew-Burke-Ernzerhof functional (GGAPBE) was used to describe the exchange-correlation potential of the electrons. ${ }^{5}$ For an accurate description of the localized $d$ electrons of $\mathrm{Cu}$, the on-site Coulomb interaction was added to the $d$ orbital of $\mathrm{Cu}$ with a $U$ value of $4.0 \mathrm{eV}$ using the rotationally invariant approach of Liechtenstein et al.. ${ }^{6,7}$ The DFT-D3 dispersion correction method of Grimme et al. was used for the long-range van der Waals interaction. ${ }^{8}$ The Brillouin zone was sampled with the gamma centered Monkhorst-Pack $k$-point grid: a $3 \times 3 \times 10 k$-point grid for the systems consisting of a monolayer and a $3 \times 3 \times 6 k$-point grid for the systems consisting of a bilayer. ${ }^{9}$ The convergence criterion for the self-consistent field calculation was set to $1 \times 10^{-6} \mathrm{eV}$ for the energy change. The lattice parameters and the atomic positions were fully relaxed until the Hellmann Feynman force converged to less than $0.01 \mathrm{eV} / \AA$.

In order to generate the potential energy surface, various stacking structures were sampled using a $9 \times 9$ grid for $a b$-plane displacements (Figure S3). The grid is divided equally for the $a$ and $b$ lattice parameters. Each stacking structure was obtained by shifting the top layer along the $a$ and $b$ directions relative to the bottom layer in the unit cell of the AA' stacking configuration. The interlayer distance was fixed at the experimental value of 3.17

$\AA$. The single-point energy calculation was performed for a total of 81 different stacking 
structures. The potential energy surface was then constructed by interpolating the DFT total energies using the bicubic spline method.

To determine the magnetic ground state of the $\mathrm{Cu}_{3}(\mathrm{TABTO})_{2} \mathrm{MOF}$, we performed a series of calculations for various spin configurations in the unit cell of the AA' stacking. In the $\mathrm{Cu}_{3}$ (TABTO $)_{2} \mathrm{MOF}$, the magnetic ion is the $\mathrm{Cu}^{2+}$ ion in a square crystal field with an unpaired electron. Since there are three $\mathrm{Cu}^{2+}$ ions in each layer, we considered two possible intralayer magnetic orderings (i.e., ferromagnetic (FM) and frustrated antiferromagnetic (FAFM) orderings). In the FAFM ordering, the spin of one $\mathrm{Cu}^{2+}$ ion is antiparallel to the spins of the other two $\mathrm{Cu}^{2+}$ ions in each layer. For the interlayer magnetic ordering, we considered two possible FM and antiferromagnetic (AFM) orderings in the chains of $\mathrm{Cu}^{2+}$ ions along the $c$-direction. As a combination of intra- and interlayer magnetic orderings, we performed geometrical optimization on a total of four spin configurations (Figure S6 and Table S2). The spin density of the four spin configurations commonly shows that the unpaired electron of the $\mathrm{Cu}^{2+}$ ion is localized on the $\mathrm{Cu}(\mathrm{NH})_{2} \mathrm{O}_{2}$ square (Figure S6). Specifically, the unpaired electron mainly resides on the $\mathrm{Cu}^{2+}$ ion $\left(0.60 \mu_{\mathrm{B}}\right)$ and is partially delocalized in the $\mathrm{N}\left(0.07 \mu_{\mathrm{B}}\right)$ and $\mathrm{O}\left(0.09 \mu_{\mathrm{B}}\right)$ atoms of the ligand. As summarized in Table $\mathrm{S} 2$, the $\mathrm{Cu}_{3}(\mathrm{TABTO})_{2}$ MOF has maximum intra- and interlayer AFM couplings at the ground state (i.e., the intralayer magnetic ordering is FAFM, and the interlayer magnetic ordering is AFM, leading to the zero total magnet moment per unit cell). This ground-state spin configuration is calculated to be $4 \mathrm{meV}$ per $\mathrm{Cu}^{2+}$ ion lower in energy than the fully FM configuration. The negligible energy difference implies that the $\mathrm{Cu}_{3}(\mathrm{TABTO})_{2} \mathrm{MOF}$ is likely to exhibit paramagnetic behavior with weak antiferromagnetic coupling. 
To investigate how effectively the carrier transport occurs, the carrier effective mass $\left(m^{*}\right)$ was estimated from the band structure. The carrier effective mass was calculated through the curvature of the band dispersion as follows.

$$
\frac{1}{m^{*}}=\frac{1}{\hbar^{2}} \frac{\partial^{2} E(k)}{\partial k^{2}}
$$

where $E(k)$ is the energy of an electron at wavevector $k, \hbar$ is the reduced Planck constant, and $m^{*}$ is the carrier effective mass. As the band dispersion gets larger, the curvature gets larger and the effective mass gets smaller. To calculate the curvature, the conduction band minimum $(\mathrm{CBM})$ and valence band maximum $(\mathrm{VBM})$ were fitted to a quadratic polynomial with $E(k)=\mathrm{a} k^{2}+\mathrm{b} k+\mathrm{c}$. Then, the value of $\partial^{2} E(k) / \partial k^{2}=2 \mathrm{a}$ was obtained through the second derivative and substituted into the equation to obtain a carrier effective mass $m^{*}$. In the CBM, the smallest effective mass was calculated to be $1.82 m_{\mathrm{e}}$ near the $\Gamma^{-}$ M segment. In the VBM, the smallest effective mass was calculated to be $0.90 m_{\mathrm{e}}$ near the $\Gamma-\mathrm{A}$ segment. 

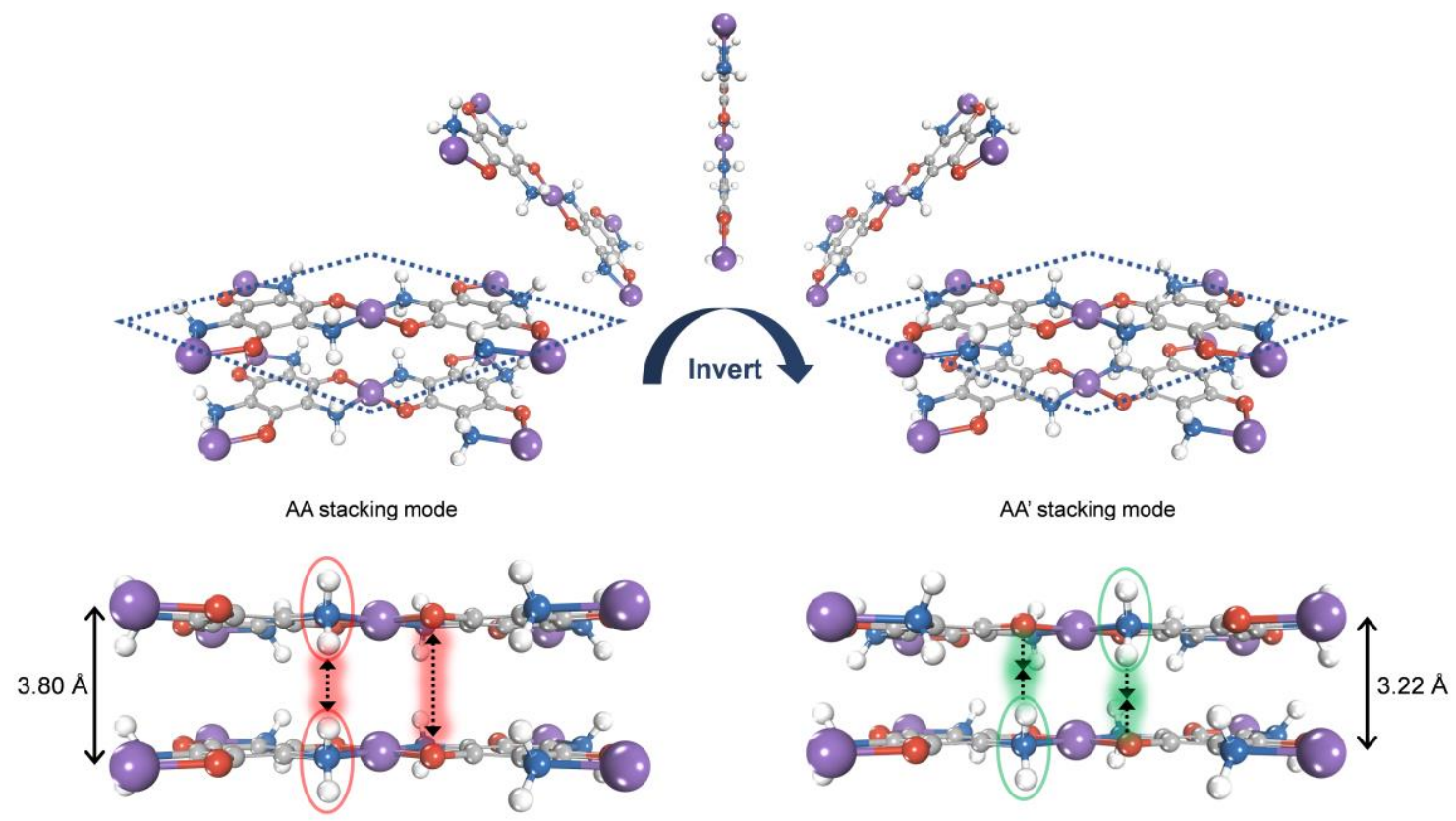

Figure S2. Comparison of the structure and the interlayer interaction between the AA stacking mode and the AA' stacking mode. The blue dotted line represents the lattice of the hexagonal unit cell. The red and green dotted arrows represent the repulsive and attractive electrostatic interactions, respectively. The red and green ellipses indicate the bulky $\mathrm{NH}_{2}$ groups. $\mathrm{C}, \mathrm{N}, \mathrm{O}, \mathrm{H}$, and $\mathrm{Cu}$ are gray, blue, red, white, and purple, respectively. 

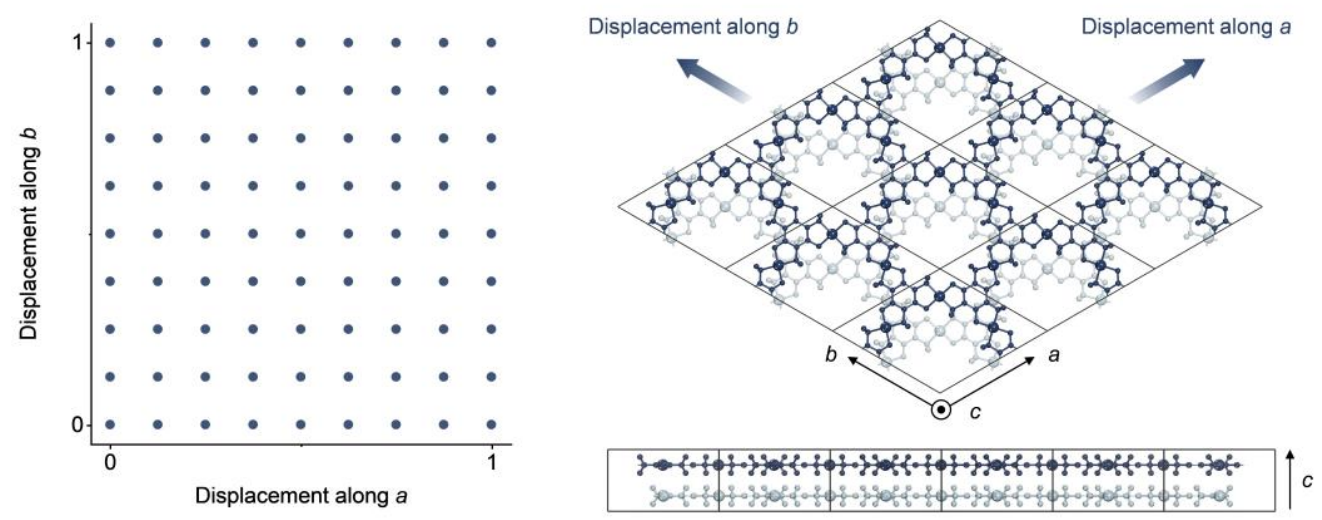

Figure S3. Generation of various stacking structures by different $a b$-plane displacements. The top layer (dark blue) is shifted along the $a$ and $b$ directions relative to the bottom layer (light gray). 

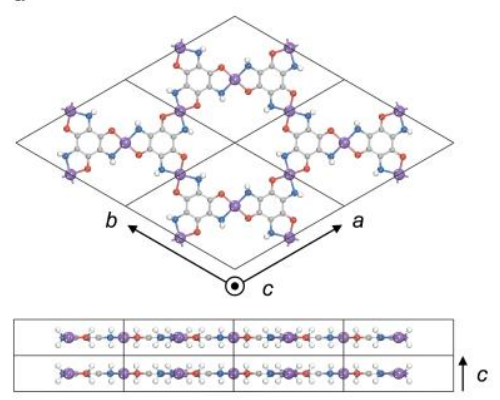

Space group : $P 6 / m$

$a=b=13.39 \AA, c=3.80 \AA$

$\alpha=\beta=90^{\circ}, y=120^{\circ}$

$E=-250.266 \mathrm{eV} /$ formula unit b
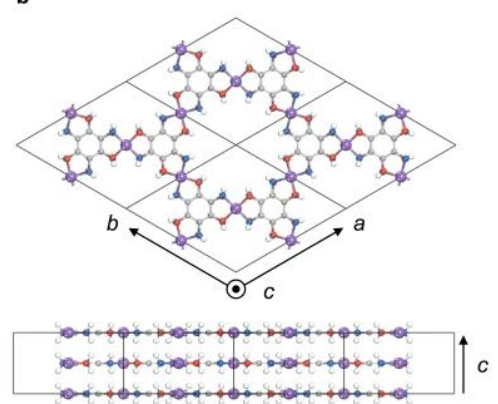

Space group : $P 6 / m c c$

$a=b=13.41 \AA, c=6.43 \AA$

$\alpha=\beta=90^{\circ}, y=120^{\circ}$

$E=-251.791 \mathrm{eV} /$ formula unit c
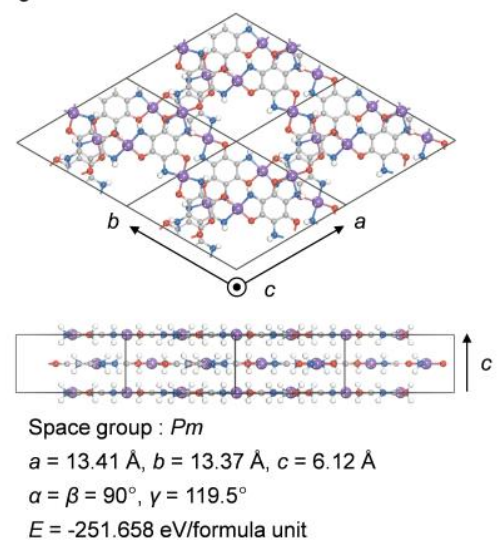

Figure S4. Crystal structure information of the $\mathrm{Cu}_{3}(\mathrm{TABTO})_{2} \mathrm{MOF}$ for the (a) AA, (b) AA', and (c) SP stacking modes. C, N, O, H, and Cu are gray, blue, red, white, and purple, respectively. 


\section{Nitrogen sorption analysis}
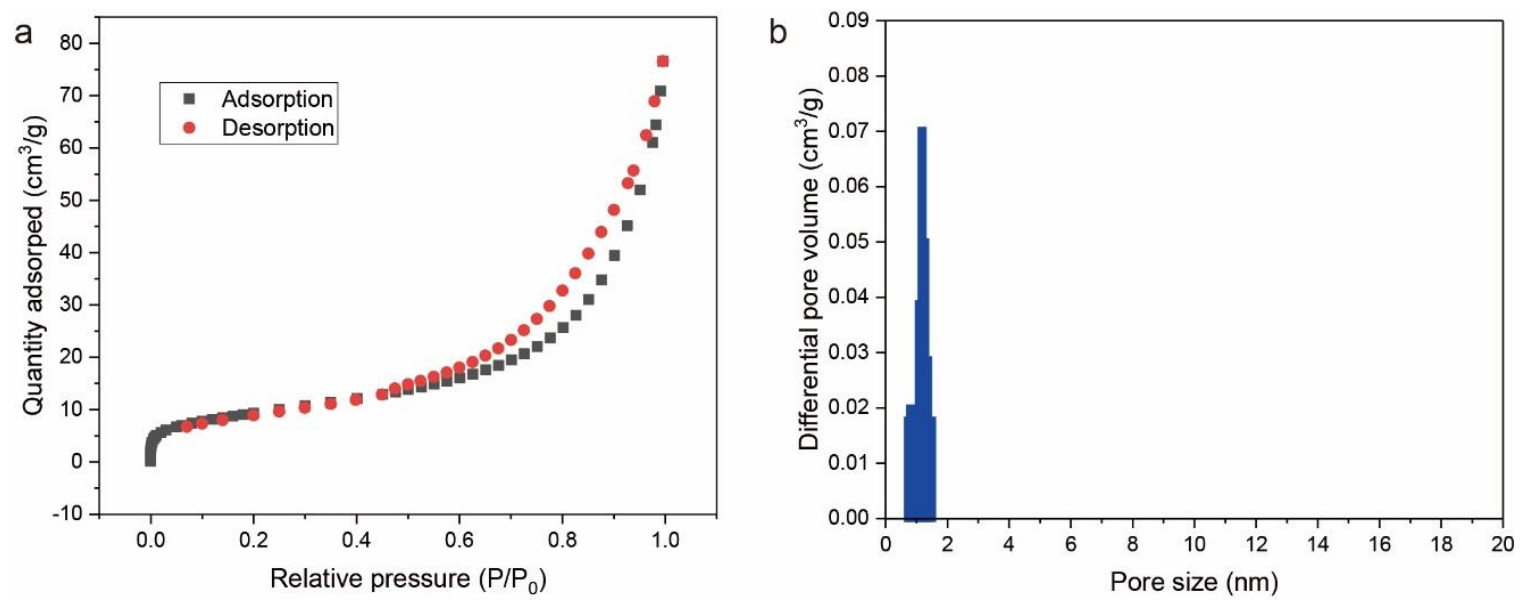

Figure S5. $\mathbf{N}_{2}$ sorption analysis of $\mathrm{Cu} 3(\mathrm{TABTO}){ }_{2}-\mathrm{Ar}$. (a) $\mathrm{N}_{2}$ sorption isotherms of $\mathrm{Cu}_{3}(\mathrm{TABTO})_{2}$-Ar powder. (b) Pore size distribution of $\mathrm{Cu}_{3}(\mathrm{TABTO})_{2}$-Ar powder. 


\section{Calculated spin density and magnetic properties of the $\mathrm{Cu}_{3}(\mathrm{TABO})_{2} \mathrm{MOF}$.}

a Spin configuration 1 Intralayer : FM / Interlayer : FM

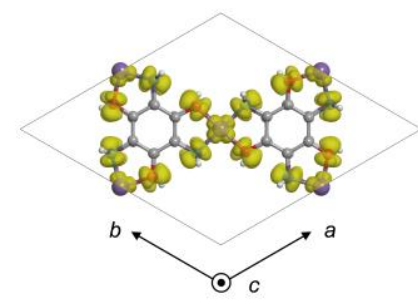

c Spin configuration 3 Intralayer: FAFM / Interlayer: FM

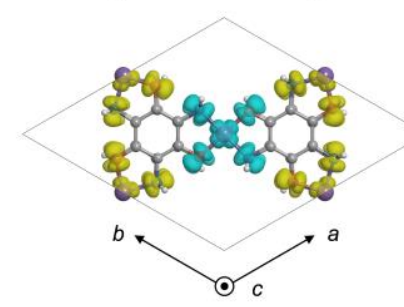

b Spin configuration 2 Intralayer: FM / Interlayer : AFM
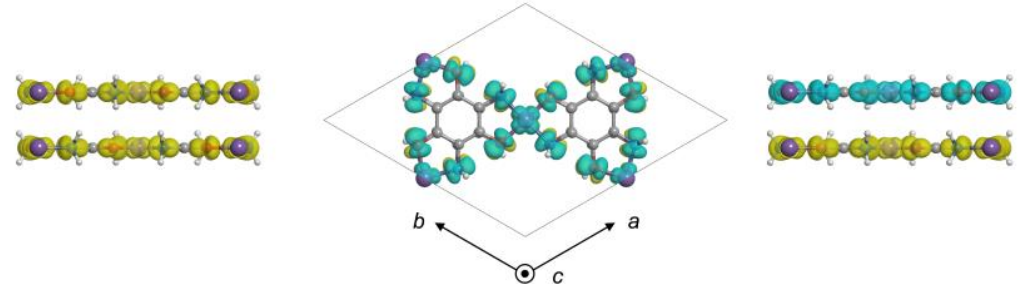

d Spin configuration 4 Intralayer: FAFM / Interlayer : AFM
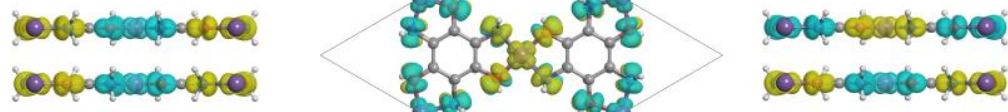

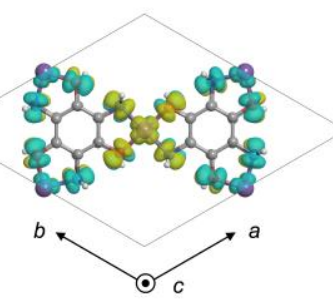

Figure S6. Calculated spin density of the $\mathrm{Cu}_{3}(\mathrm{TABO})_{2} \mathrm{MOF}$ in the AA' stacking mode with four different magnetic configurations: (a) Spin configuration 1, (b) spin configuration 2, (c) spin configuration 3, and (d) spin configuration 4. Yellow and bluish green isosurfaces represent the spin density for up-spin and down-spin electrons, respectively. C, $\mathrm{N}, \mathrm{O}, \mathrm{H}$, and $\mathrm{Cu}$ are gray, blue, red, white, and purple, respectively. 


\section{Calculated intra- and interlayer magnetic orderings, magnetic moment, and the total DFT energies of the $\mathrm{Cu}_{3}$ (TABTO) 2 MOF in the AA' stacking mode.}

Table S2. Intra- and interlayer magnetic orderings, magnetic moment, and the total DFT energies of the $\mathrm{Cu}_{3}(\mathrm{TABTO})_{2} \mathrm{MOF}$ in the $\mathrm{AA}^{\prime}$ stacking mode with four different spin configurations.

\begin{tabular}{|c|c|c|c|c|c|c|c|}
\hline & \multirow{2}{*}{$\begin{array}{l}\text { Intralayer } \\
\text { magnetic } \\
\text { ordering }\end{array}$} & \multirow{2}{*}{$\begin{array}{l}\text { Interlayer } \\
\text { magnetic } \\
\text { ordering }\end{array}$} & \multicolumn{4}{|c|}{ Magnetic moment $\left(\mu_{\mathrm{B}}\right)$} & \multirow{2}{*}{$\begin{array}{c}\text { Energy } \\
\left(\mathrm{meV} / \mathrm{Cu}^{2+} \text { ion }\right)\end{array}$} \\
\hline & & & $\begin{array}{l}\text { Unit } \\
\text { cell }\end{array}$ & $\mathrm{Cu}$ & $\mathrm{N}$ & $\mathrm{O}$ & \\
\hline Spin configuration 1 & FM & FM & 6.00 & 0.60 & 0.07 & 0.09 & -83930.3 \\
\hline Spin configuration 2 & FM & AFM & 0.00 & 0.60 & 0.07 & 0.09 & -83931.2 \\
\hline Spin configuration 3 & FAFM & FM & 2.00 & 0.60 & 0.07 & 0.09 & -83933.4 \\
\hline Spin configuration 4 & FAFM & AFM & 0.00 & 0.60 & 0.07 & 0.09 & -83934.3 \\
\hline
\end{tabular}


9. Calculated charge density of the $\mathrm{Cu}_{3}(\mathrm{TABTO})_{2} \mathrm{MOF}$.

a

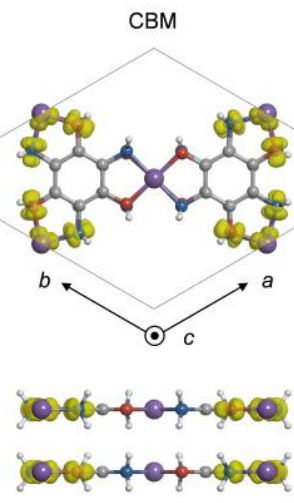

b
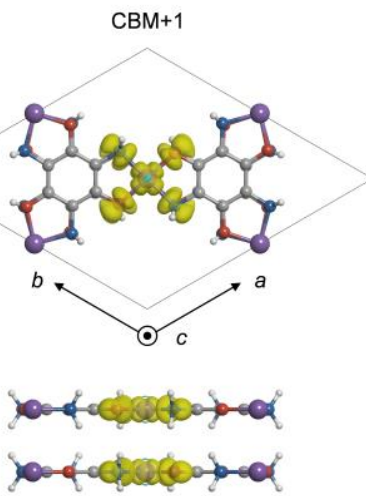

c

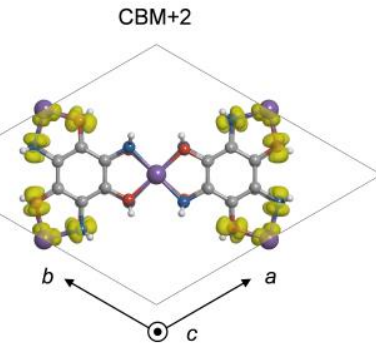

cofo-to-ogecel

copo-to-odoce

Figure S7. Charge density of the (a) $\mathrm{CBM}$, (b) $\mathrm{CBM}+1$, and (c) $\mathrm{CBM}+2$. 
10. Calculated band structure and projected density of states (PDOS) of the $\mathrm{Cu}_{3}$ (TABTO)2 MOF.
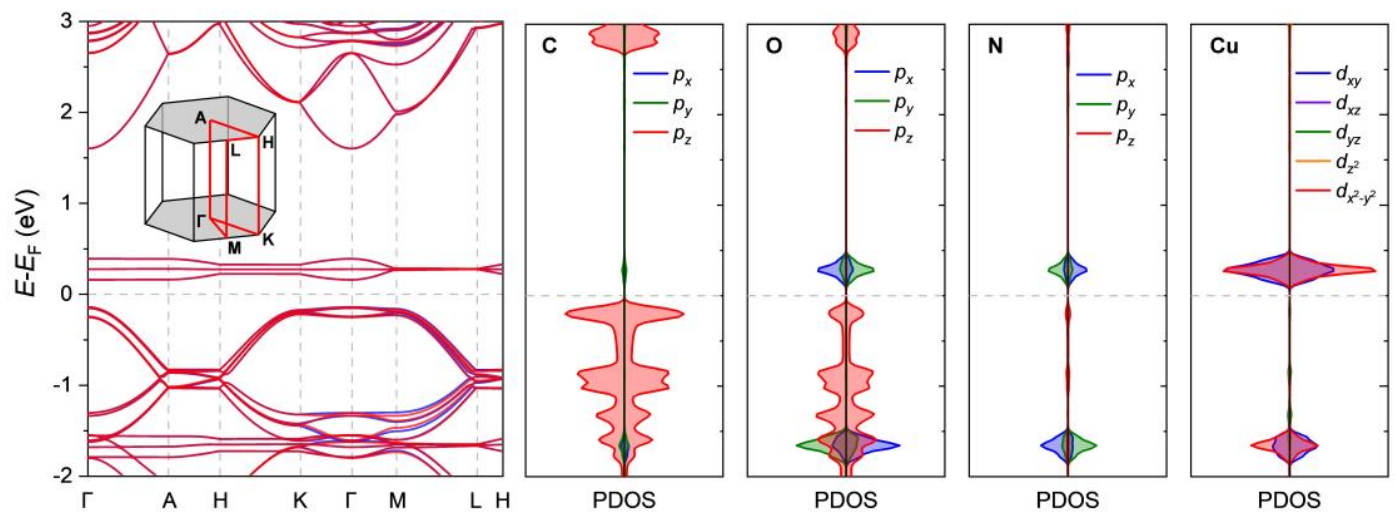

Figure S8. Calculated band structure and projected density of states (PDOS) of the $\mathrm{Cu}_{3}(\mathrm{TABTO})_{2} \mathrm{MOF}$ with AA' stacking mode at the magnetic ground state. 
11. Hall effect measurement at room temperature.

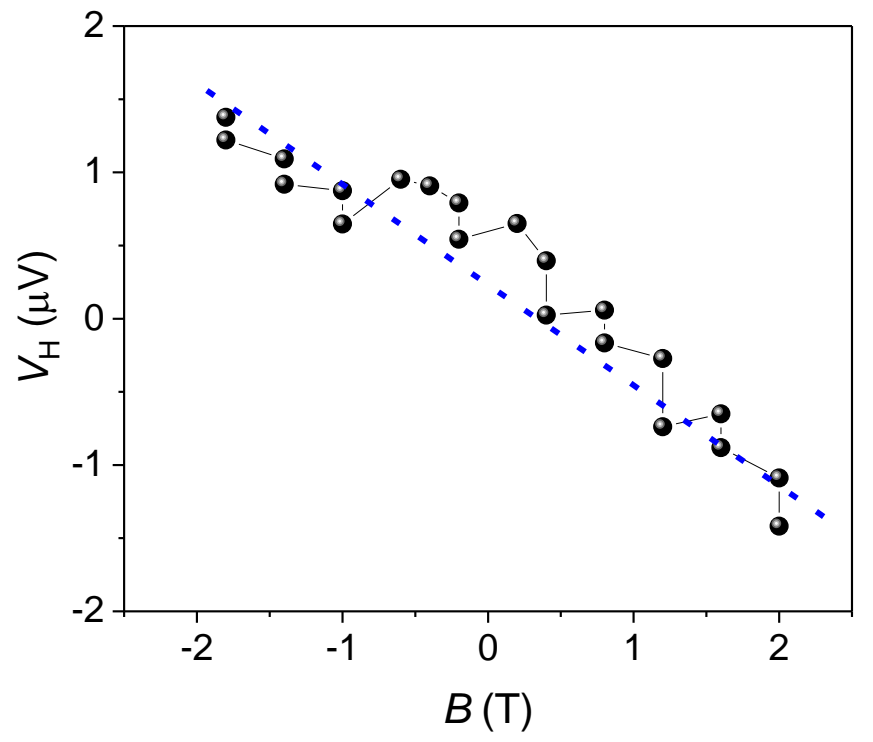

Figure S9. Hall effect measurement of the iodine-doped $\mathrm{Cu}_{3}(\mathrm{TABTO})_{2}$-Ar pellet at room temperature. 
12. Estimation of the hole binding energy.

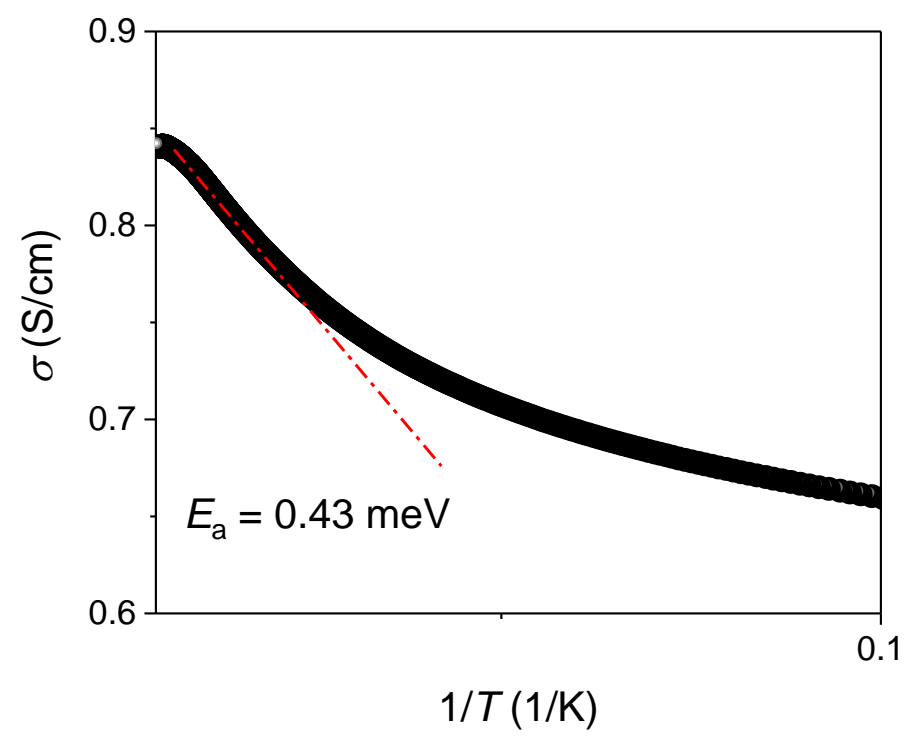

Figure S10. Plot of electrical conductivity $(\sigma)$ versus $1 / T$. Using the Arrhenius plot $(\sigma=$ $\sigma_{0}(T) e^{-\frac{E_{A}}{k_{B} T}}$, we obtain the hole binding energy, i.e. an activation energy from the valence band into the acceptor energy level. The activation energy, fit from the linear region from $30 \mathrm{~K}$ to $200 \mathrm{~K}$, is $0.43 \mathrm{meV}$. 
13. The mechanism of conversion of $\mathrm{Cu}(\mathrm{II})$ to $\mathrm{Cu}(\mathrm{I})$.

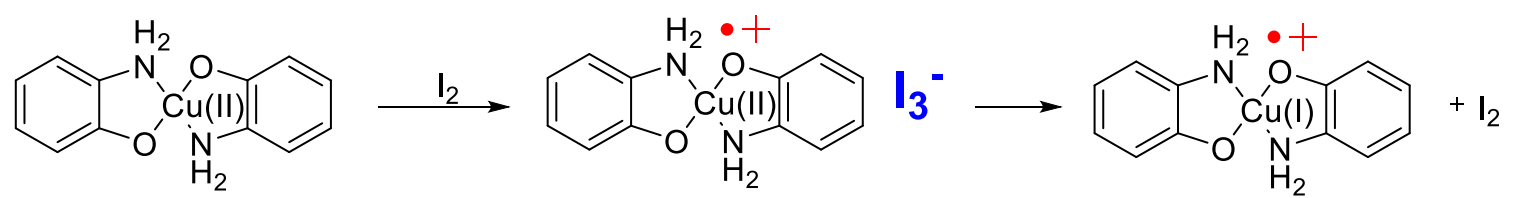

Scheme S1. The mechanism of conversion of $\mathrm{Cu}(\mathrm{II})$ to $\mathrm{Cu}(\mathrm{I})$. This conversion is similar to that of $\mathrm{CuI}_{2}$ to $\mathrm{CuI}$. 
14. EPR spectra of pristine and iodine-doped $\mathrm{Cu}_{3}(\mathrm{TABTO})_{2}-\mathrm{Ar}$.

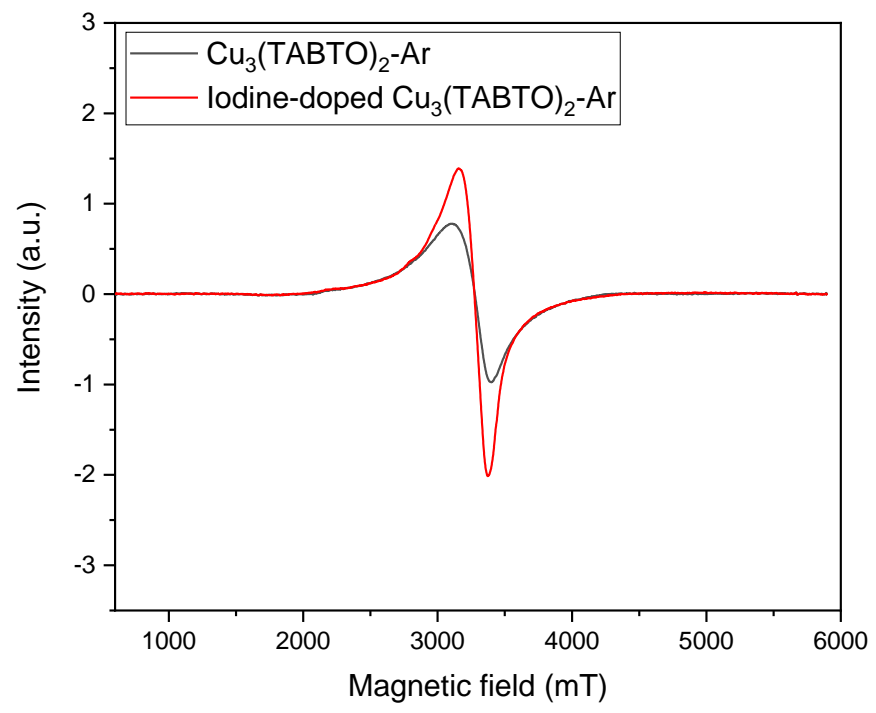

Figure S11. EPR spectra of pristine and iodine-doped $\mathrm{Cu}_{3}(\mathrm{TABTO})_{2}-\mathrm{Ar}$. 
15. Synchrotron XRD data of pristine and iodine-doped $\mathrm{Cu}_{3}(\mathrm{TABTO})_{2}-\mathrm{Ar}$.

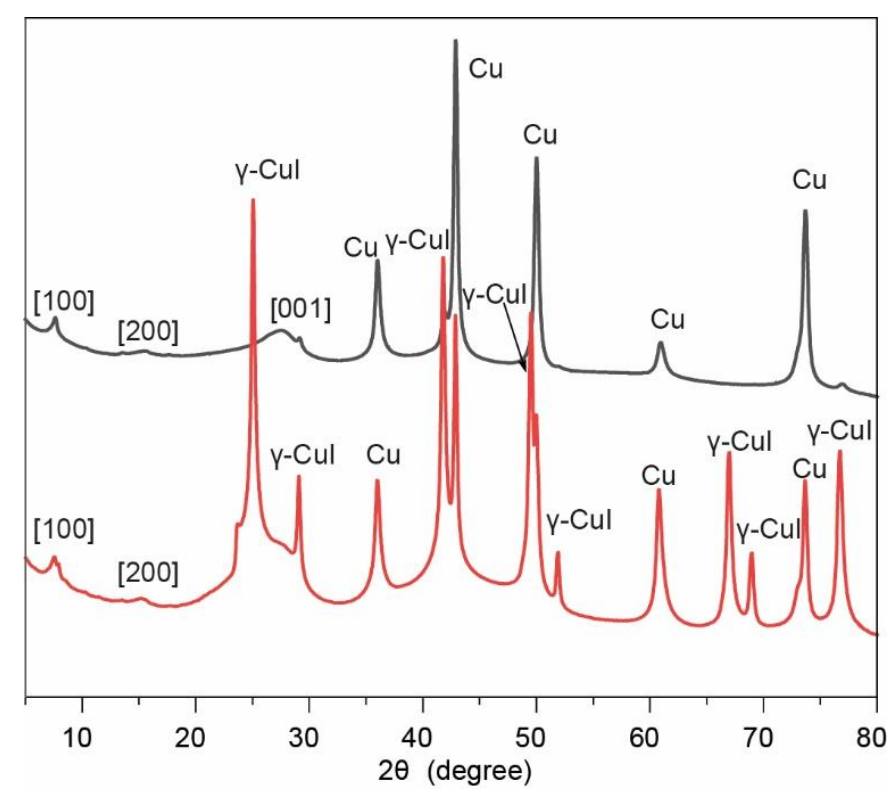

Figure S12. Synchrotron X-ray diffraction (XRD) data of pristine and the iodine-doped $\mathrm{Cu}_{3}(\mathrm{TABTO})_{2}-\mathrm{Ar}$.

X-ray diffraction (XRD; Synchrotron-based) measurements of pristine and iodine-doped $\mathrm{Cu}_{3}(\mathrm{TABTO})_{2}-\mathrm{Ar}$ showed that $\gamma$-CuI was formed and the crystalline structure of $\mathrm{Cu}_{3}(\mathrm{TABTO})_{2}$-Ar was retained after iodine doping, suggesting that $\mathrm{I}_{3}{ }^{-}$and $\mathrm{CuI}$ are present in the pores of $\mathrm{Cu}_{3}(\mathrm{TABTO})_{2}$ (Figure S12). ${ }^{10-12}$ These results indicate that this MOF might be used to align guest species within the channels. ${ }^{13-14}$ 


\section{Explanations of the structure and electrical conductivity of $\mathrm{Cu}_{3}(\mathrm{TABTO})_{2}$ using DFT calculations.}

We did more calculations to understand the structure and intrinsic electronic properties of the as-synthesized pristine $\mathrm{Cu}_{3}(\mathrm{TABTO})_{2}$. We first investigated the origin of $\mathrm{Cu}(\mathrm{I})$, which is not present in the ideal structure described in the main text. Based on the XPS analysis, we speculate that the partial reduction of $\mathrm{Cu}(\mathrm{II})$ to $\mathrm{Cu}(\mathrm{I})$ is from oxidation of $1,3,5$ triamino-2,4,6-benzenetriol with the conversion of $\mathrm{NH}_{2}$ to $\mathrm{NH}$ during the synthesis. To test this hypothesis, we did DFT calculations for fragment models with ideal $\mathrm{Cu}\left(\mathrm{NH}_{2}\right)_{2} \mathrm{O}_{2}$ square-planar geometry and $\mathrm{Cu}\left(\mathrm{NH}_{2}\right)(\mathrm{NH}) \mathrm{O}_{2}$ square-planar geometry. In the ideal $\mathrm{Cu}\left(\mathrm{NH}_{2}\right)_{2} \mathrm{O}_{2}$ square-planar geometry, the atomic magnetic moment and charge of the $\mathrm{Cu}$ atom were $0.57 \mu_{\mathrm{B}}$ and $0.79 e$, which indicates the presence of $\mathrm{Cu}(\mathrm{II})$ (Figure $\mathrm{S} 13 \mathrm{a}$ ). The $\mathrm{Cu}$ atom in the $\mathrm{Cu}\left(\mathrm{NH}_{2}\right)(\mathrm{NH}) \mathrm{O}_{2}$ had atomic magnetic moment and charge of $0.00 \mu_{\mathrm{B}}$ and $0.56 e$, thus $\mathrm{Cu}(\mathrm{I})$ (Figure $\mathrm{S} 13 \mathrm{~b}$ ). These results suggest that the conversion of $\mathrm{NH}_{2}$ to $\mathrm{NH}$ leads to the reduction of $\mathrm{Cu}(\mathrm{II})$ to $\mathrm{Cu}(\mathrm{I})$. While $\mathrm{Cu}(\mathrm{I})$ is present in the (overall) squareplanar geometry, the $\mathrm{Cu}(\mathrm{I})$-containing "sub-unit" has trigonal-planar geometry and the $\mathrm{Cu}$ $\mathrm{O}$ bond that is present in the ideal $\mathrm{Cu}\left(\mathrm{NH}_{2}\right)_{2} \mathrm{O}_{2}$ structure, is broken. The $\mathrm{N}$ and $\mathrm{O}$ atoms in the oxidized ligand form double bonds with the $\mathrm{C}$ atoms, which is consistent with the highresolution $\mathrm{N}$ 1s and $\mathrm{O}$ 1s XPS spectra.

We thus also calculated a bulk $\mathrm{Cu}_{3}(\mathrm{TABTO})_{2}$ structure in which there was a mixture of square-planar $\mathrm{Cu}\left(\mathrm{NH}_{2}\right)_{2} \mathrm{O}_{2}$ and trigonal-planar $\mathrm{Cu}\left(\mathrm{NH}_{2}\right)(\mathrm{NH}) \mathrm{O}_{2}$, which is likely closer to the structure of the synthesized pristine $\mathrm{Cu}_{3}(\mathrm{TABTO})_{2}$. The atomic magnetic moment and the Bader charge of the $\mathrm{Cu}$ atoms with the trigonal-planar geometry in the $\mathrm{Cu}\left(\mathrm{NH}_{2}\right)(\mathrm{NH}) \mathrm{O}_{2}$ square were $0.01 \mu_{\mathrm{B}}$ and $0.59 e($ i.e., $\mathrm{Cu}(\mathrm{I}))$, and those of $\mathrm{Cu}$ atoms with the square-planar 
geometry in the $\mathrm{Cu}\left(\mathrm{NH}_{2}\right)_{2} \mathrm{O}_{2}$ were $0.59 \mu_{\mathrm{B}}$ and $0.94 e$ (i.e., $\mathrm{Cu}(\mathrm{II})$ ) (Figure $\mathrm{S} 14 \mathrm{a}$ ). The calculated band structure and the projected density of states (PDOS) (Figure S14b) indicate that this model for the $\mathrm{Cu}_{3}(\mathrm{TABTO})_{2}$ is a semiconductor with a band gap of $0.20 \mathrm{eV}$ at the gamma point, similar to the ideal $\mathrm{Cu}_{3}(\mathrm{TABTO})_{2}$ that has been described in the main text.

a
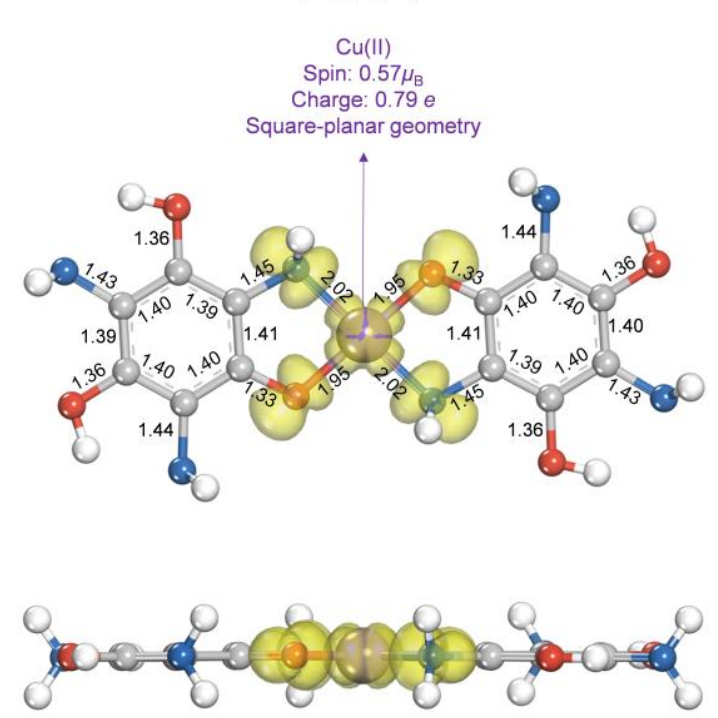

b
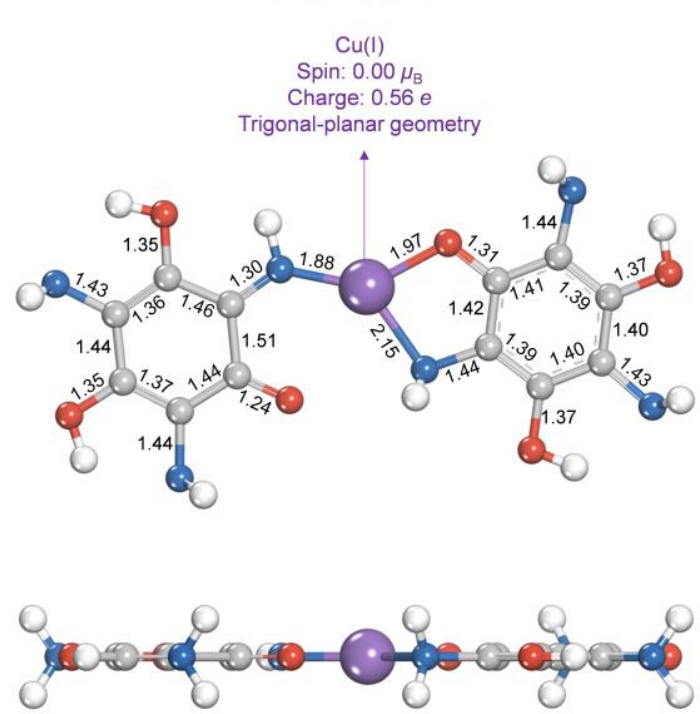

Figure S13. Optimized structures of fragment models with (a) $\mathrm{Cu}\left(\mathrm{NH}_{2}\right)_{2} \mathrm{O}_{2}$ and (b) $\mathrm{Cu}\left(\mathrm{NH}_{2}\right)(\mathrm{NH}) \mathrm{O}_{2}$. Yellow isosurface represents the spin density. Number indicates the bond length in angstrom units. Note that although the mixed valence $\mathrm{Cu}$ (I and II) in $\mathrm{Cu}_{3}(\mathrm{TABTO})_{2}$ have different coordination geometries (i.e., square-planar geometry for $\mathrm{Cu}$ (I) and trigonal-planar geometry for $\mathrm{Cu}(\mathrm{II})$ ), the (overall) $2 \mathrm{D}$ structure of $\mathrm{Cu}_{3}(\mathrm{TABTO})_{2}$ is retained. 

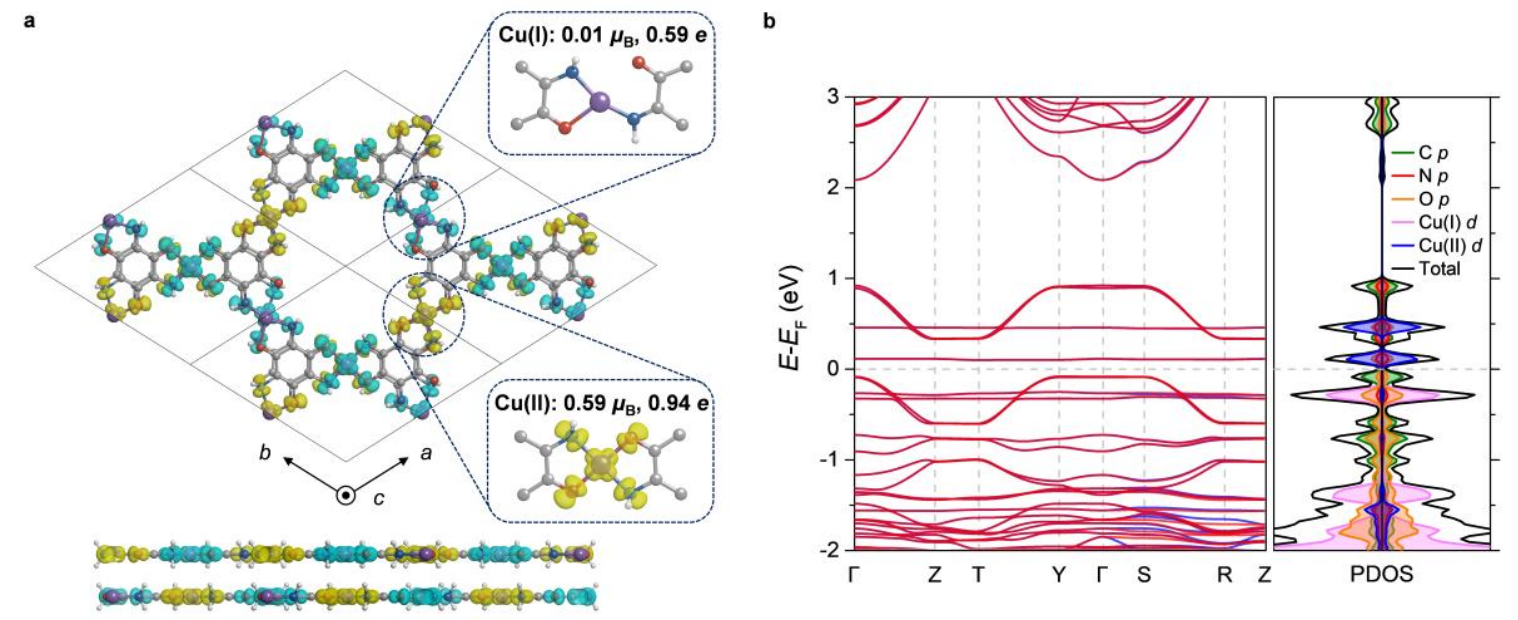

Figure S14. (a) Optimized structure that is meant to model the experimental pristine $\mathrm{Cu}_{3}(\mathrm{TABTO})_{2}$ consisting of four square-planar $\mathrm{Cu}\left(\mathrm{NH}_{2}\right)_{2} \mathrm{O}_{2}$ squares and two trigonalplanar $\mathrm{Cu}\left(\mathrm{NH}_{2}\right)(\mathrm{NH}) \mathrm{O}_{2}$. Yellow and bluish green isosurfaces represent the spin density for up-spin and down-spin electrons, respectively. $\mathrm{C}, \mathrm{N}, \mathrm{O}, \mathrm{H}$, and $\mathrm{Cu}$ atoms are gray, blue, red, white, and purple, respectively. (b) Calculated band structure and projected density of states of the pristine $\mathrm{Cu}_{3}(\mathrm{TABTO})_{2}$. 
17. SEM images of pristine and (b) iodine-doped $\mathrm{Cu}_{3}(\mathrm{TABTO})_{2}-\mathrm{Ar}$.
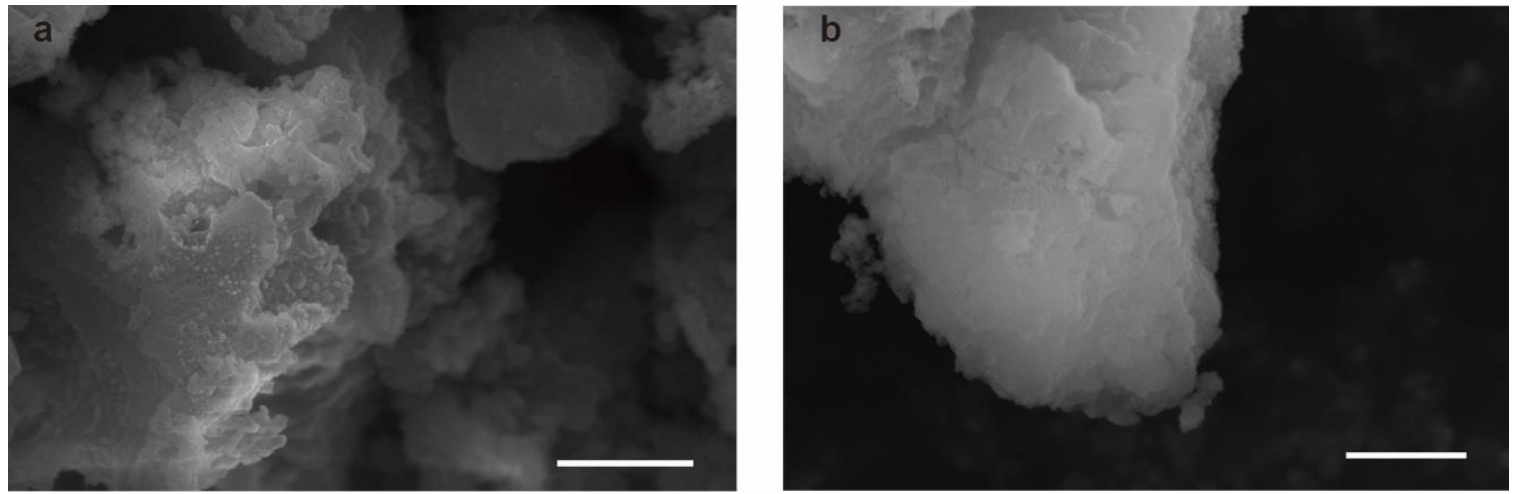

Figure S15. SEM images of (a) pristine and (b) iodine-doped $\mathrm{Cu}_{3}(\mathrm{TABTO})_{2}$-Ar. Scale bar: $1 \mu \mathrm{m}$. 
18. TEM images of pristine and (b) iodine-doped $\mathrm{Cu}_{3}(\mathrm{TABTO})_{2}-\mathrm{Ar}$.
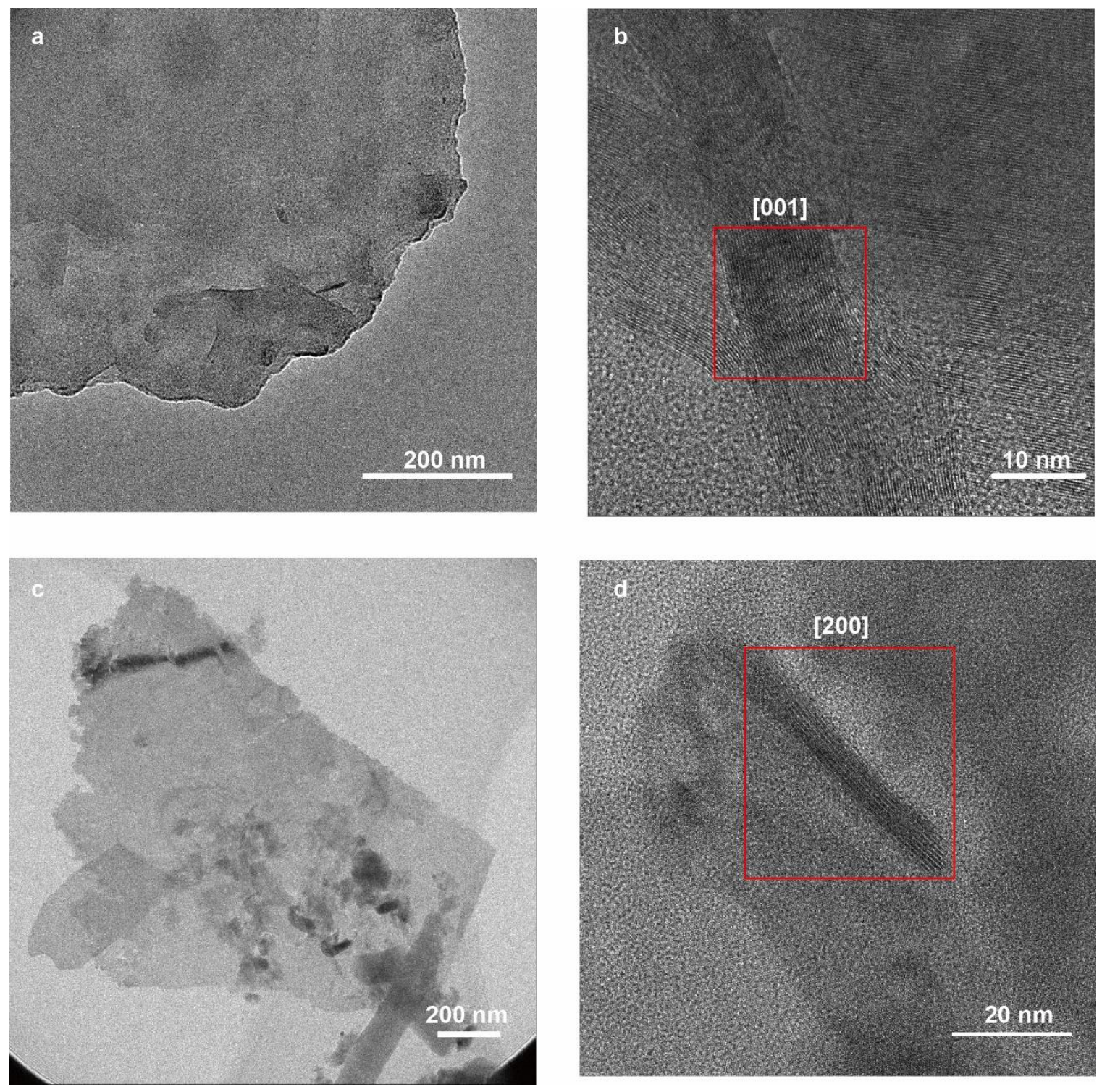

Figure S16. HR-TEM images of ( $a$ and $b$ ) pristine and ( $c$ and $d$ ) iodine-doped $\mathrm{Cu}_{3}(\mathrm{TABTO})_{2}$-Ar. An operating voltage of $200 \mathrm{kV}$ was used for HR-TEM imaging. 
19. AFM images of pristine and (b) iodine-doped $\mathrm{Cu}_{3}(\mathrm{TABTO})_{2}$-Ar.
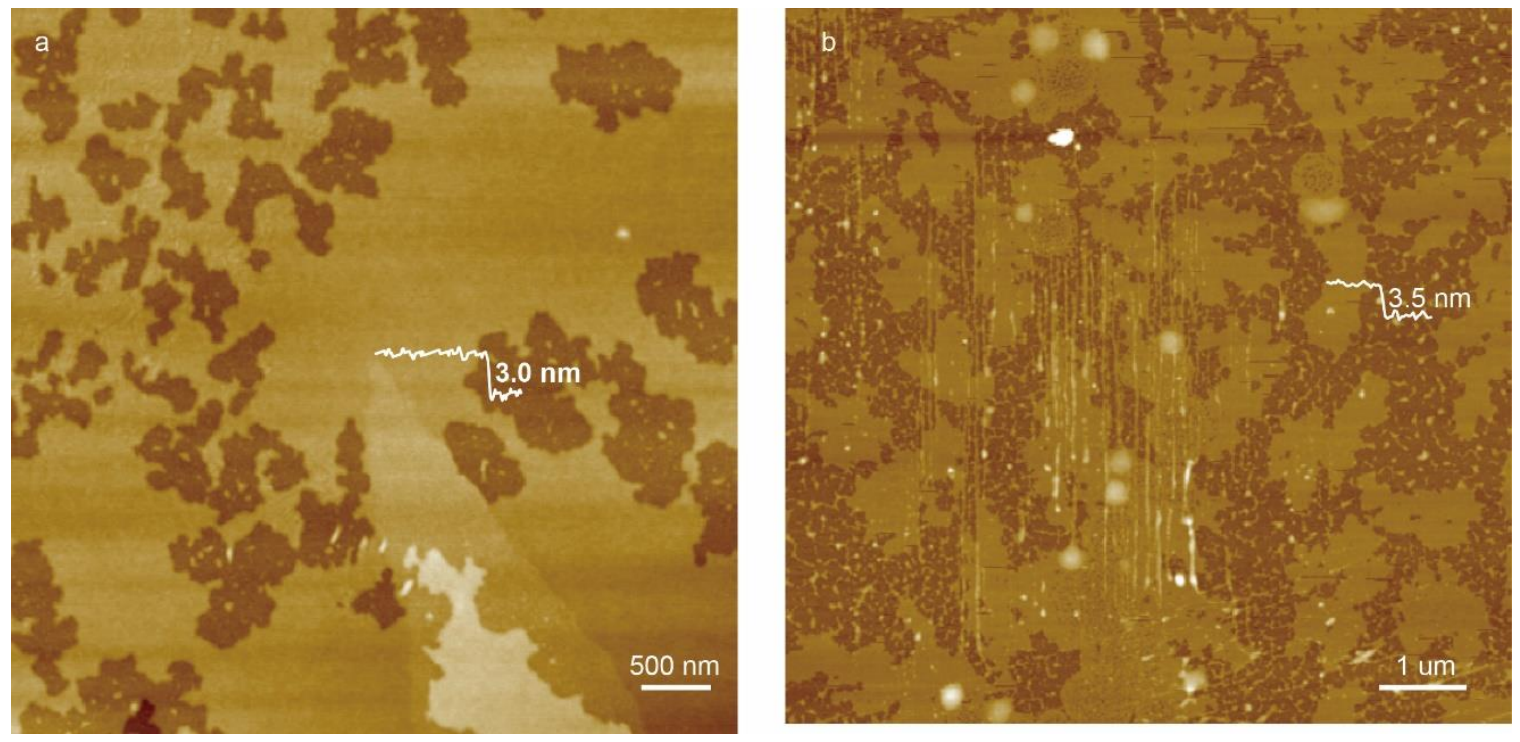

Figure S17. AFM image of (a) pristine and (b) iodine-doped $\mathrm{Cu}_{3}(\mathrm{TABTO})_{2}-\mathrm{Ar}$. The samples were deposited on $\mathrm{Si} / \mathrm{SiO}_{2}$ substrate and imaged in air. 


\section{Cyclic voltammograms of $\mathrm{Cu}\left(\mathrm{NO}_{3}\right)_{2}$ and 1,3,5-triamino-2,4,6-benzenetriolate.}

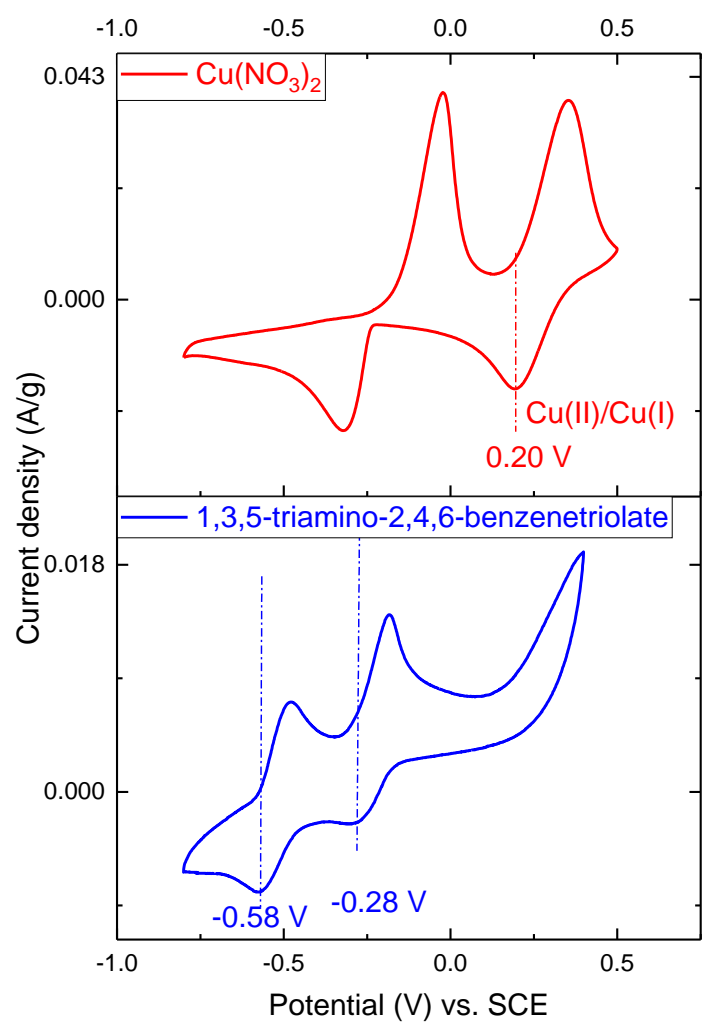

Figure S18. Cyclic voltammograms $\left(50 \mathrm{mV} \mathrm{S}^{-1}\right)$ of $\mathrm{Cu}\left(\mathrm{NO}_{3}\right)_{2}(1 \mathrm{mM}$ in $1 \mathrm{M} \mathrm{KCl}$ aqueous solution) and 1,3,5-triamino-2,4,6-benzenetriolate (1 $\mathrm{mM}$ in $1 \mathrm{M} \mathrm{KCl}$ aqueous solution) at a platinum working electrode in air.

To provide more information on the redox reaction of 1,3,5-triamino-2,4,6-benzenetriol and $\mathrm{Cu}(\mathrm{II})$, the cyclic voltammograms of $\mathrm{Cu}\left(\mathrm{NO}_{3}\right)_{2}$ and 1,3,5-triamino-2,4,6benzenetriolate (1,3,5-triamino-2,4,6-benzenetriol and 1.5 equiv. ethyldiamine) were measured. As shown in Figure S18, the reduction potential of $\mathrm{Cu}(\mathrm{II}) / \mathrm{Cu}(\mathrm{I})$ at $0.20 \mathrm{~V}$ is more positive than the two reduction potentials of 1,3,5-triamino-2,4,6-benzenetriolate at -0.58 and $-0.28 \mathrm{~V}$. The reduction of $\mathrm{Cu}(\mathrm{II})$ to $\mathrm{Cu}(\mathrm{I})$ by 1,3,5-triamino-2,4,6-benzenetriolate is thus reasonable. 
21. FT-IR spectra of freshly synthesized and 3-month old iodine-doped $\mathrm{Cu}_{3}$ (TABTO)2-Ar stored in air.

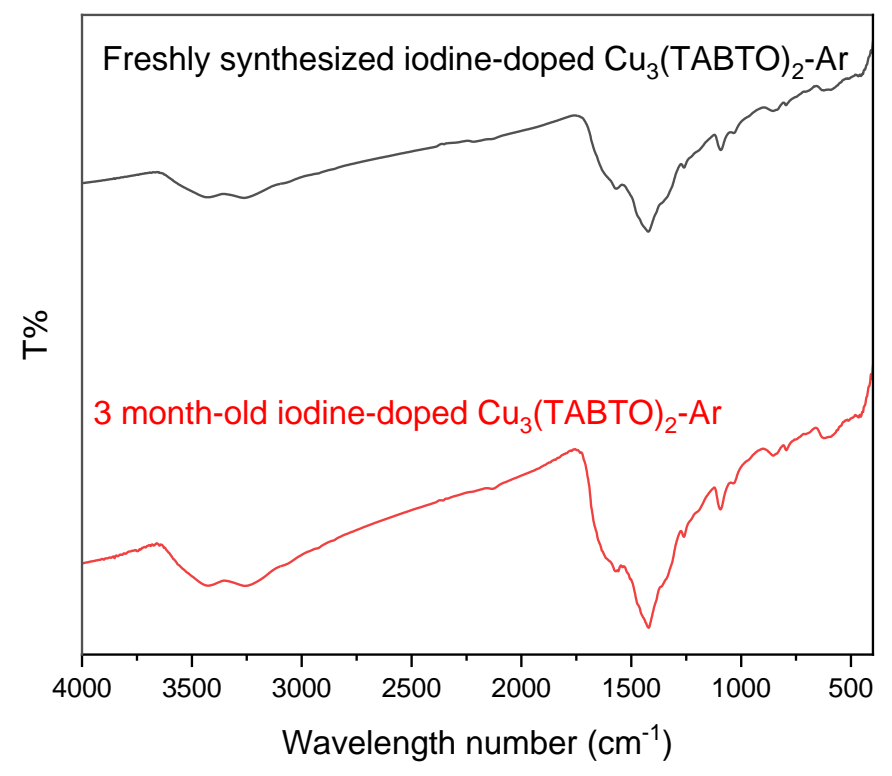

Figure S19. FT-IR spectra of freshly synthesized and 3-month old iodine-doped $\mathrm{Cu}_{3}(\mathrm{TABTO})_{2}-\mathrm{Ar}$ stored in air. 
22. Survey XPS spectra of freshly synthesized and 3-month old iodine-doped $\mathrm{Cu}_{3}(\mathrm{TABTO})_{2}$-Ar stored in air.

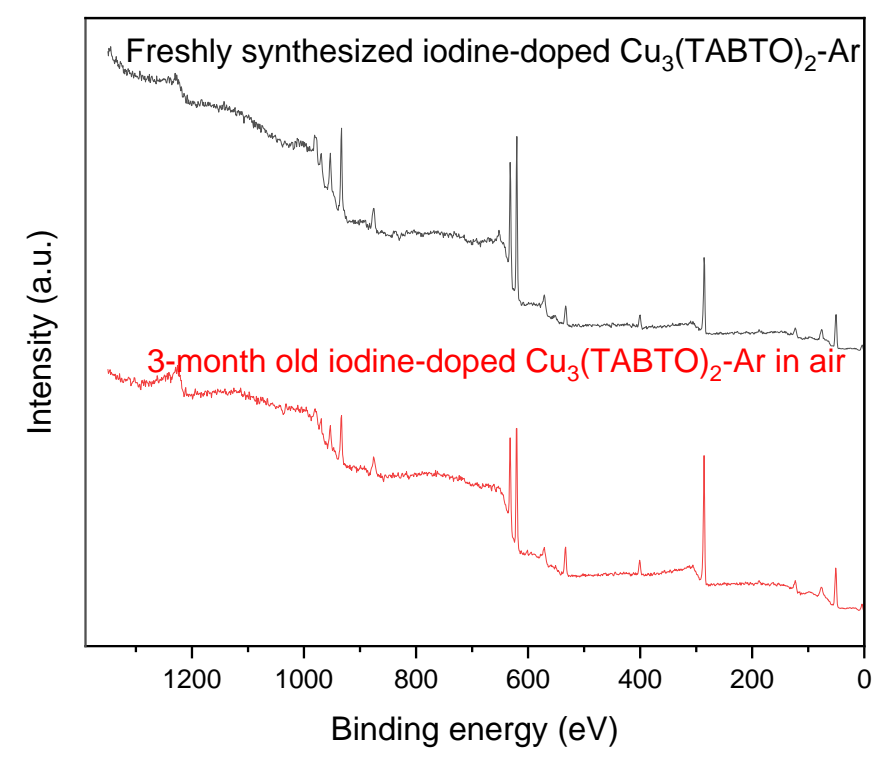

Figure S20. Survey XPS spectra of freshly synthesized and 3-month old iodine-doped $\mathrm{Cu}_{3}(\mathrm{TABTO})_{2}-\mathrm{Ar}$ stored in air. 


\section{Cu2p XPS spectra of $\mathrm{Cu}_{3}(\mathrm{TABTO})_{2}$-Air-1 before and after iodine-doping.}
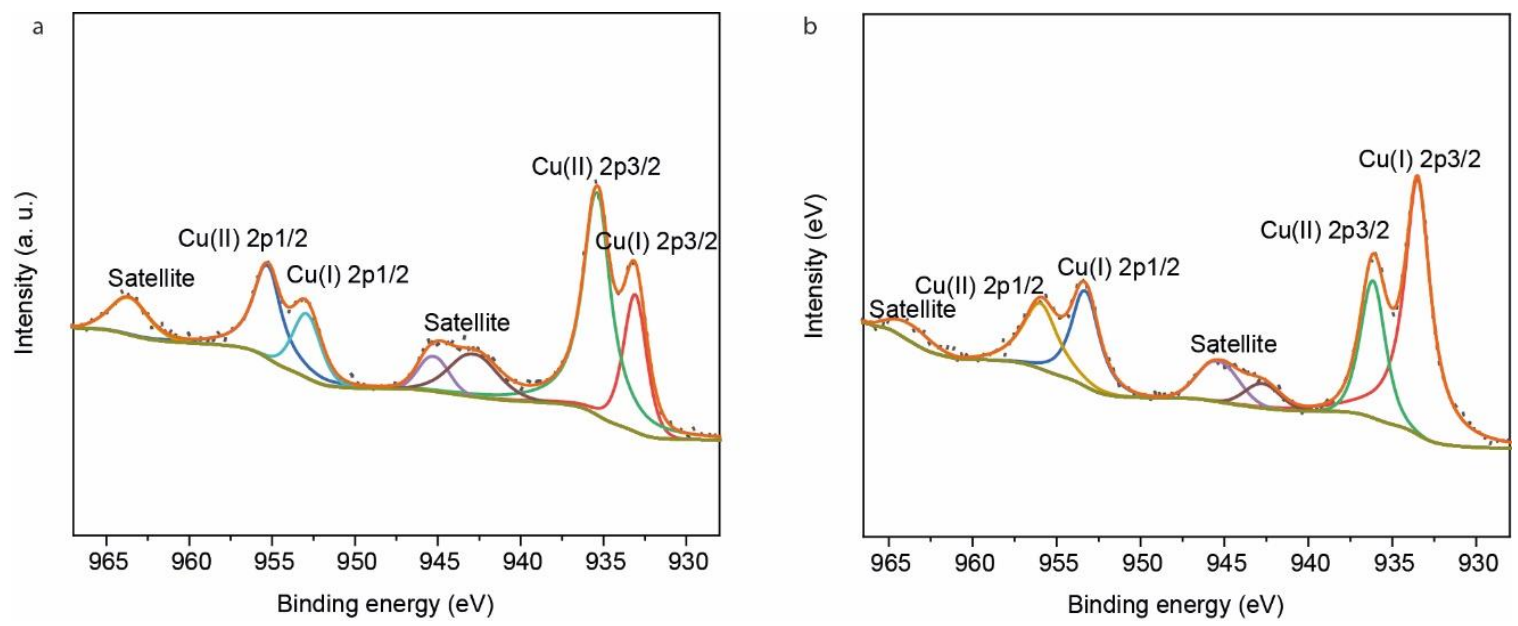

Figure S21. $\mathrm{Cu} 2 \mathrm{p}$ XPS spectra of $\mathrm{Cu}_{3}(\mathrm{TABTO})_{2}$-Air-1 before (a) and after iodine-doping (b).

$\mathrm{Cu} 2 \mathrm{p}$ XPS analysis gives a $\mathrm{Cu}(\mathrm{II}) / \mathrm{Cu}(\mathrm{I})$ ratio of $5 / 2$ in pristine $\mathrm{Cu}_{3}(\mathrm{TABTO})_{2}$-Air-1, and a $\mathrm{Cu}(\mathrm{II}) / \mathrm{Cu}(\mathrm{I})$ ratio of $2 / 5$ in iodine-doped $\mathrm{Cu}_{3}(\mathrm{TABTO})_{2}$-Air-1, suggesting that $\mathrm{Cu}$ (II) was reduced to $\mathrm{Cu}(\mathrm{I})$ after iodine-doping. The $\mathrm{Cu} / \mathrm{I}$ ratio in $\mathrm{Cu}_{3}(\mathrm{TABTO})_{2}$-Air-1 is $1 / 2$. The iodine-doped $\mathrm{Cu}_{3}(\mathrm{TABTO})_{2}$-Air-1 pellet is insulating, suggesting the metallic property of iodine-doped $\mathrm{Cu}_{3}(\mathrm{TABTO})_{2}-\mathrm{Ar}$ is mainly due to the presence of copper metal and $\gamma-\mathrm{CuI}$. 


\section{References}

(1) Seo, J.-M.; Noh, H.-J.; Jeong, H. Y.; Baek, J.-B. Converting Unstable ImineLinked Network into Stable Aromatic Benzoxazole-Linked One via PostOxidative Cyclization. J. Am. Chem. Soc. 2019, 141, 11786-11790.

(2) Kresse, G.; Furthmüller, J. Efficient Iterative Schemes for Ab Initio Total-Energy Calculations Using a Plane-Wave Basis Set. Phys. Rev. B 1996, 54, 11169-11186.

(3) Kresse, G.; Furthmüller, J. Efficiency of Ab-Initio Total Energy Calculations for Metals and Semiconductors Using a Plane-Wave Basis Set. Comp. Mater. Sci. 1996, 6, 15-50.

(4) Kresse, G.; Joubert, D. From Ultrasoft Pseudopotentials to the Projector Augmented-Wave Method. Phys. Rev. B 1999, 59, 1758-1775.

(5) Perdew, J. P.; Burke, K.; Ernzerhof, M. Generalized Gradient Approximation Made Simple. Phys. Rev. Lett. 1996, 77, 3865-3868.

(6) Liechtenstein, A. I.; Anisimov, V. I.; Zaanen, J. Density-Functional Theory and Strong Interactions: Orbital Ordering in Mott-Hubbard Insulators. Phys. Rev. B 1995, 52, R5467.

(7) Wang, L.; Maxisch, T.; Ceder, G. Oxidation Energies of Transition Metal Oxides within the GGA + U Framework. Phys. Rev. B 2006, 73, 195107.

(8) Grimme, S.; Antony, J.; Ehrlich, S.; Krieg, H. A Consistent and Accurate Ab Initio Parametrization of Density Functional Dispersion Correction (DFT-D) for the 94 Elements H-Pu. J. Chem. Phys. 2010, 132, 154104. 
(9) Monkhorst, H. J.; Pack, J. D. Special Points for Brillouin-Zone Integrations. Phys. Rev. $B$ 1976, 13, 5188-5192.

(10) Madhuri, K. P.; John, N. S.; Angappane, S.; Santra, P. K.; Bertram, F. Influence of Iodine Doping on the Structure, Morphology, and Physical Properties of Manganese Phthalocyanine Thin Films. J. Phys. Chem. C 2018, 122, 2807528084.

(11) Shiozawa, H.; Bayer, B. C.; Peterlik, H.; Meyer, J. C.; Lang, W.; Pichler, T. Doping of metal-organic frameworks towards resistive sensing. Sci. Rep. 2017, 7, 2439.

(12) Jin, E.; Asada, M.; Xu, Q.; Dalapati, S.; Addicoat, M. A.; Brady, M. A.; Xu, H.; Nakamura, T.; Heine, T.; Chen, Q.; Jiang, D. Two-Dimensional sp² CarbonConjugated Covalent Organic Frameworks. Science 2017, 357, 673- 676.

(13) Inokuma, Y.; Yoshioka, S.; Ariyoshi, J.; Arai, T.; Hitora, Y.;Takada, K.; Matsunaga, S.; Rissanen, K.; Fujita, M. Nature 2013, 495,461-466.

(14) Lee, S.; Kapustin, E. A.; Yaghi, O. M. Science 2016, 353, 808-811. 